\title{
Stress and occupational burnout in a population of Polish doctors - Organizational-professional and non-professional-social predictors
}

\author{
Marta Makara-Studzińska ${ }^{1, A-B, D \oplus}$, Antoni Wontorczyk ${ }^{2, D-F} \oplus$, Bernadetta Izydorczyk $k^{2, A-D \oplus}$ \\ ${ }^{1}$ Division of Health Psychology, Faculty of Health Sciences, Collegium Medicum, Jagiellonian University, Kraków, Poland \\ ${ }^{2}$ Institute of Applied Psychology, Jagiellonian University, Kraków, Poland \\ A - Research concept and design, B - Collection and/or assembly of data, C - Data analysis and interpretation, \\ $D$ - Writing the article, E-Critical revision of the article, F- Final approval of article
}

Makara-Studzińska M, Wontorczyk A, Izydorczyk B. Stress and occupational burnout in a population of Polish doctors - Organizationalprofessional and non-professional-social predictors. Ann Agric Environ Med. 2020; 27(3): 456-468. doi: 10.26444/aaem/110846

\begin{abstract}
Ibstract
Introduction and objective. Numerous studies have found that doctors are exposed to stress and burnout at work. In consequence, these processes lead to a decrease in the quality of life. The study aimed to determine whether professional burnout, understood as a cognitive existential process, is related to stress at work and if any of the four dimensions of burnout are its predictor. The study also analyzed relations between organizational-professional and non-professionalsocial factors and burnout and stress at work.

Materials and method. 318 doctors ( 210 women, 108 men), aged 27 - 8, participated in the study. Link Burnout Questionnaire (LBQ) was used to measure burnout, and the Perceived Stress Scale (PSS-10) to measure the variable describing the current level of stress.

Results. Occupational burnout is related to stress. Two of its symptoms: exhaustion and lack of a sense of professional effectiveness, are important predictors for the sense of stress experienced by the examined group of doctors. The individuals who are in a partner relationship (but not marriage) experienced a stronger sense of non-professional effectiveness than those who were single. Being in an informal relationship is related to the level of stress and lack of a sense of professional effectiveness. The level of stress, as well as all burnout indicators, are connected with the function of a team leader and having passion. The frequency of taking leave and using social networks is related to the level of stress and burnout.

Conclusions. Problems related to burnout in doctors, and therefore people professionally involved in helping and treating, must not be underestimated, as evidenced by the results of the presented study Professional burnout of doctors leads to somatic and psychological problems. Doctors suffering from occupational burnout need support and psychological assistance the same as any other professional group.
\end{abstract}

\section{Key words}

burnout syndrome, doctors, stress at work, burnout, non-professional-social predictors, organizational-professional predictors

\section{INTRODUCTION}

The level of perceived stress related to the work of a doctor providing medical services in contemporary Polish outpatient and inpatient health care is connected to various stressors that can undoubtedly lead to the development of burnout. According to the literature, the most frequently mentioned risk factors of occupational burnout include personality traits, attitude to work and burden related to the doctor's satisfaction, organization and working conditions $[1,2]$. Attempts to observe the connections between socio-demographic and psychosocial determinants of burnout in contemporary doctors have frequently become the subject of research $[3,4,5,6,7]$. Occupational burnout is usually presented from the perspective of the theoretical model developed by Cristine Maslach (Maslach Burnout Inventory-MBI), describing three dimensions of professional burnout among medical staff: emotional exhaustion, depersonalization and a sense of lack of personal achievement [8]. A review of studies on professional burnout among medical staff (particularly

Address for correspondence: Antoni Wontorczyk, Jagiellonian University, Institute of Applied Psychology

E-mail: antoni.wontorczyk@uj.edu.pl

Received: 21.11.2018; accepted: 03.07.2019; first published: 18.07.2019 concerning nurses) draws attention to the subject of the effectiveness and satisfaction with work, physical and mental fatigue in professional work $[9,10,11,12,13,14,15]$ and personality factors $[2,14]$. Studies of occupational burnout among doctors also indicates the diversity and ambiguity of relationships between doctors' occupational burnout and demographic factors, such as age, gender, marital status $[18,19,20,21,22,23]$, personality $[2,21,22,23,24,25,26]$, professional experience and professional workload of doctors $[13,15,18,19,21,24,27,28]$.

The relationship between current stress experienced in their daily lives by Polish doctors performing their professional duties and daily measurement of the whole set of variables describing the level of daily work-load, is a definitely much less known area of research. Significant socio-economic variables that may be related to the level of everyday stress and the development of burnout are a set of variables rarely tested simultaneously in the same group of doctors, including the measurement of both workload and the role of non-working life (taking time off or pursuit of interests, as well as having permanent emotional relationships). A study was therefore undertaken which had to take into account the entire set of socio-economic variables and symptoms essential for the functioning of doctors in the Polish reality. Among 
the explanatory variables tested in this study were levels of stress and burnout in the medical professio, including both demographic variable, as well as various socio-economic variables regarding professional and personal load (pursuit of interests and emotional relation). The literature lacks scientific reports showing a description of the whole set of socio-economic and demographic variables in the context of occupational stress in Polish doctors who work every day in Polish health care facilities. Little research data is found that would empirically document how much workload (e.g. number and time of work performed, number of work places), time spent on rest and vacation, time devoted to pursuing one's own interests, and having an emotional relationship with life partners, which can be important in generating stress and burnout.

Lack of research on these topics concerns particularly the group of doctors involved in the everyday work with apatient that is not an emergency, which is the case of surgeons, neurosurgeons, oncologists, and other medical specialists working in emergency medicine. The doctor dealing with patient diagnosis and treatment in an outpatient and inpatient setting encounters permanent occupational stress [2]. It is worth noting that a necessary condition for the development of burnout is life under chronic stress, manifesting through the presence of symptoms of emotional disorders, depression, physical symptoms and somatic disorders in everyday personal and professional life [29]. Dudek enumerates 10 components of stress and a sense of mental burden attributing them to the complexity of work, lack of rewards at work, a sense of insecurity caused by work organization, lack of social contacts, a sense of danger, physical nuisance, unpleasant working conditions, lack of control, lack of social support and a sense of responsibility [29]. Sęk developed the cognitivecompetence model of stress and burnout highlighting the specific and non-specific occupational stressors. All these factors depending on the assessment of the person's competence, coping strategies, personal and environmental resources affect emotional burnout, depersonalization and reduced involvement of physicians at work [30].

The conducted research, based on the above-mentioned model, showed that in this professional group there is a relationship between emotional exhaustion which affects the depersonalization of patients and a decrease in their professional involvement. On the other hand, low professional satisfaction has a negative effect on emotional exhaustion. Emotional exhaustion results primarily from the stress load. The key element of burnout, which is depersonalization, is primarily emotional exhaustion, but also assessment of the occupational situation through the prism of the threat and use of avoidance control [30]. Furthermore, it is worth mentioning that the contemporary globalized society expects the employee to work almost 24 hours a day, including public holidays (Saturdays and Sundays). As some studies conclude, this requirement has become virtually a social norm leading even to the deterioration of mental health [31]. This phenomenon has also been observed in Poland. The average Pole, including the contemporary Polish doctor, generally works during statutory working hours - frequently with overtime. Moreover, overtime work, to some extent, has become an acceptable social norm for the average Pole.

According to the literature, numerous risk factors for the development of occupational stress result from the daily burdens associated with work structure, e.g. work time, number and working conditions $[2,31]$. According to the Euro Health Consumer Index, Poland is 31st among 36 countries due to the level of professional overwork among doctors [33]. At the same time, the doctor-patient relationship requires psychosocial skills, such as openness, kindness, empathy, and high communication skills. Research on professional stress and the quality of life among doctors is becoming increasingly important and necessary because they can promote a better understanding of risk factor, as well as protectors against the development of occupational stress and burnout in the professional group in question. Stress, experienced as life progresses with growing distractor strength, usually increases the individual's sense of danger and loss, which exacerbates stress and promotes burnout $[2,34,35]$.

Objective and subjective reasons motivate doctors to work every day and exceed their psychophysical capacity with great number of patient, or work at more than one place, which in connection with everyday occupational stress can lead to-fast burnout. A burnt-out doctor, in time becomes less effective at work and less empathic and friendly to patients and colleagues. Not surprisingly, doctors working in hospices, palliative care, nursing homes, working with people with disabilities, in the departments of oncology, paediatric or geriatric wards, experience increased stress and burnout.

The development of this constant phenomena arouses scientific interest. One in particular is above-average professional stress resulting from overloading with excess work in the general health-care environment, i.e. in doctors of various specialties, different professional experience and age, in which every day professional activities do not involve extremely difficult medical procedures of immediate emergency and noticeable suffering and pain in patients, as in case of emergency medicine, oncology, neurosurgery and similar specialties [34].The cognitive and emotional competences required in the doctor's profession, e.g. empathy, give a humanistic character (warmth and trust in communication, sensitivity to harm and suffering) to the doctor's everyday activities, and affect the patient's sense of satisfaction with the quality of medical care in the daily work of a specialist who admits more and more patients every day, regardless of the emotional burden. On the one hand, stress in the daily treatment of patients experiencing various disease symptoms and injuries improves job satisfaction; on the other hand, it causes exhaustion and various health disorders [35].

In a study by Ogińska-Bulik [36], a correlation was found between persistent stress at work and the health problems of those who experience it. Ogińska-Bulik [36] suggests that predictors for the development of disorders are different in the group of people with a high level of stress, compared to those with low levels. Similar results were obtained by Ostrowski [35], who showed that occupational stress in doctors affects health. Most pathogenic components of stress at work include: responsibility, a sense of mental burden associated with the work complexity and time-consuming work (e.g. overtime, frequent rosters, lack of rewards at work, a sense of insecurity) and burdens resulting from the sense of insecurity, and lack of family and social support. According to Ostrowski, marriage is a salutogenetic variable reducing the number of mental health problems in doctors [35]. It reduces the number of mental problems in working people.

Nevertheless, the results of research on the strength of dependence between stress and burnout in literature sources 
are ambiguous. The literature indicates research results that describe various subjective determinants of occupational burnout in the medical profession, especially in the group of nurses $[2,9,10,11,12,13]$ and doctors with surgical and palliative specialties [34]. However, there are no studies that indicate the measurement of psychosocial or socio-economic factors that could be important in the development of stress and burnout in doctors practicing every day in conservative medicine, working on a daily basis in various health care facilities.

\section{OBJECTIVES}

Numerous studies have been conducted on the nature and mechanisms of occupational burnout since the early 1970 s [36]. However, knowledge in this regard is still incomplete and incoherent. Some researchers assume equivalency between occupational stress and burnout. Many definitions of burnout can be found in the literature. Research is being conducted on various paradigms, various theoretical and research models, using various tools $[37,38,39,40]$. Therefore, the study had five aims:

1) To understand the relationship between the level of stress experienced at work by doctors and the burnout syndrome that they experience. It was also important to discover which of the four symptoms of professional burnout, understood as a cognitive existential process [41], is the most strongly associated with stress. According to Maslach, the risk factors for burnout are found in the context of the work, not in the professional content, and in the basic nature of tasks related to helping other people at work. Therefore, it is important to emphasize the importance of organizational factors as the key mechanisms for developing burnout syndrome [42]. However, the intermediary influence of personality determinants should be kept in mind as well as organizational-professional, non-professionalsocial determinants. With this in mind, it was decided to examine:

2) Significant differences between the surveyed Polish doctors with high and low levels of stress in terms of verified organizational-professional factors and socio-economic factors (type and number of medical specializations, academic titles, number of current jobs, number of years in the basic workplace, frequency of job changes, commuting between jobs, episodes of taking up work abroad, performing the function of a team leader at work).

3) Significant differences between the surveyed Polish doctors with high and low levels of stress in terms of verified demographic and non-professional-social factors (age, being in a relationship with a partner, married or single, frequency of taking leave during the year, treatment and taking antidepressants, and practicing non-professional activities);

4) If and to what extent verified organizational-professional and socio-economic factors influence the level of stress and professional burnout in Polish doctors;

5) If and to what extent verified non-professional-social factors (having and frequency of everyday passions and interests, close emotional relationships: partner, marital, treatment due to stress and mental discomfort (taking antidepressants), influence of the level of stress and professional burnout in Polish doctors.
The following variables were extracted:

a) Organizational-professional and socio-economic factors - a set of indicators describing the level of a personal load. This variable was defined on the basis of indicators describing: the type and number of medical specializations possessed, the scientific title held, current number of jobs, number of years in the basic work place, frequency of job changes, commuting time between jobs, episodes of taking up work abroad, and performing the function of a team leader.

b) Demographic factors and non-professional and socialfactors - a variable describing age, gender, marital status of the doctors, health behaviours regarding current professional activity (number of rosters a month, frequency of taking leave during the year, taking antidepressants, non-professional activity, i.e. frequency of activities related to the pursuit of interests and passions in everyday life, having an account on a social network).

c) Currently perceived stress. This described the level of stress experienced by the doctor in his/her daily life and work.

d) Occupational burnout. This variable described the level of feelings related to professional work, i.e. the level of: psychophysical exhaustion, involvement in the relationship with a patient, and level of effectiveness and efficiency of performed professional tasks and satisfaction accompanying the work performed.

\section{MATERIALS AND METHOD}

The research was carried out between April 2017 - June 2018 and included doctors working in hospitals located in the southern and central-eastern parts of Poland: Małopolskie, Lubelskie and Mazovian provinces. Two types of medical facilities were selected for the study: three university clinical hospitals and eight district hospitals. Each of the university clinical hospitals had at least 10 clinics from which the examined doctors were recruited. In the case of the second group of medical facilities (district hospitals), the respondents worked in ten different departments. Such a territorially wide area of research was selected due to two facts: 1) the phenomenon observed in Poland that physicians work at several positions within a given county or even province; and 2) the different internal structure of district hospitals in terms of the number of departments.

All study subjects were informed about the aim and procedure of the study. Every examined doctor agreed to participate in the research and complete questionnaires. Respondents had a right to resign from participation at every step of the study. The interviewers trained by researchers carried out the study. They personally contacted the doctors, provided them with research materials, presented the test procedure, and then collected the completed questionnaires after a few days at a set time.

Ethical approval was obtained from the relevant institutional Ethical Review Committees, and the research conducted in accordance with national and international regulations and guidelines.

Written informed consent was obtained from all participants.

Purposive sampling of the study group was used. 318 doctors: 210 women (66\%) and 108 men (34\%), aged 27 - 86 (M $=47, \mathrm{SD}=11.21)$ were enrolled in the study. It wasa assumed that 330 doctors would be examined. Exclusion criteria were 
as follows: part-time work as a doctor (less than full-time, 15 hours per week), citizenship and nationality other than Polish, work outside Poland in previous years, present and declared mental disorders with the history of their treatment, especially depression requiring pharmacological treatment five respondents, i.e. $1.6 \%$ of the total study group. Another seven respondents ( $2 \%$ of the total study group) were excluded due to insufficiently completed questionnaires.

A proprietary questionnaire containing a set of questions about socio-economic data was used to measure socioeconomic and demographic factors (type and number of medical specializations possessed, academic title, current number of parallel jobs, number of years in the primary work place, frequency of job changes in previous years), time spent commuting between jobs, episodes of taking up work abroad, performing the function of the team leader), questions about demographic data (gender, age, marital status: single, widower/widow, partnership, marriage), questions about health behaviours within the scope of current professional activity (measurement of current work load - number of rosters in the month, frequency of taking leave during a year, taking antidepressants), questions about non-professional activity (frequency of practicing activity related to the pursuit of interests and passions in everyday life, having an account on a social network).

Link Burnout Questionnaire (LBQ) was used to measure the variable of burnout, and the Perceived Stress Scale (PSS-10) was used to measure the variable describing the current stress level. The LBQ questionnaire is an adaptation of a 24-item tool by Massimo Santinello, developed by Jaworowska [41]. The examined person uses a 6-point scale to assess feelings related to their professional work. Each item is scored on a 6 -point Likert scale ranging from 1 (never) - 6 (very often) The tool examines four domains: psychophysical exhaustion (Exhaustion-Energy), involvement in relationships with patients (Lack of Commitment - Commitment), effectiveness in performed work (Lack of Efficacy - Effectiveness) and existential expectations (Disappointment - Satisfaction).

Psychophysical exhaustion is understood as the loss of energy resources, experiencing fatigue and tension during work. Commitment is expressed in the form of conscientious and individual treatment of each patient. Its opposite is indifference, distancing and hostility. Effectiveness at work is the effectiveness in the tasks being performed. Satisfaction is expressed in the form of passion and enthusiasm accompanying the work being performed. Its opposite is disappointment with the results. The four sub-scales obtained satisfactory internal reliability indicators in the current study as follows: Exhaustion-Energy, Crombach Alfa = 0.82; Lack of Commitment - Commitment, Crombach Alfa = 0.57; Lack of Efficacy - Effectiveness Crombach Alfa =0.76); Disappointment - Satisfaction; Crombach Alfa $=0.88$.

PSS-10 by Cohen (Polish study by Juczyński, Bulik [43]) is a tool for self-assessment of the intensity of stress related to the current life situation. Ten questions identify the level of current perceived stress as the assessment of effectiveness in dealing with life events. The results allow to identify the level of current perceived stress in the examined physicians. The obtained raw result was transformed into standardized units, interpreted according to the sten scale. The higher the score, the greater the severity of the currently experienced stress. In the presented study, the PSS-10 scale obtained satisfactory internal reliability (Cronbach Alpha $=0.89$ ).

\section{RESULTS}

Statistical analysis of the research results included:

1) Measurement of socio-economic and demographic variables, as well as measurement of the severity of current stress and burnout; for this purpose, descriptive statistics (arithmetic mean, median, standard deviation) were used.

2) Measuring the strength of the intensity of experienced stress in the current life of the respondents, including the division of the whole group into two categories: doctors with high and low level of perceived stress, as determined on the basis of the mean and median values.

3) Measurement of the strength of the relationship between the surveyed physicians with high and low level of perceived stress, and occupational burnout and socio-economic and demographic variables; for this purpose, a correlation analysis was carried out using Cramer's V factor (socioeconomic variables - qualitative variables) and Pearson's $\mathrm{r}$ (socio-economic variables quantitative and burnout).

Characteristics of socio-economic and demographic variables in the examined doctors. The examined doctors were characterized by varied work experience in the profession: from $1-56$ years $(\mathrm{M}=20.18, \mathrm{SD}=11.50)$ and a different number of years of employment in the basic place of work $(0.5-48$ years, $\mathrm{M}=14.10, \mathrm{SD}=10.84)$. The doctors' working hours were also varied. The respondents declared from $2-120$ working hours a week $(\mathrm{M}=53,84, \mathrm{SD}=21,86)$ and from no rosters to even 20 rosters in the month $(\mathrm{M}=3.23$, $\mathrm{SD}=3.98)$. The vast majority of the participants worked in public institutions $(\mathrm{N}=285,90 \%)$ without having the position of team leader $(\mathrm{N}=237,75 \%)$, and did not work abroad in the medical profession $(\mathrm{N}=305,96 \%)$. Most of the respondents $(\mathrm{N}=174,55 \%)$ had not changed their jobs in the last five years. The highest percentage of respondents did not have a scientific title $(\mathrm{N}=250,79 \%)$, had completed one specialization $(\mathrm{N}=$ $197,62 \%)$, and at the time of the study worked in two different jobs $(\mathrm{N}=87,27 \%)$. In terms of marital status, the majority of respondents were in their first marriage $(\mathrm{N}=199,63 \%)$. The respondents were dominated by: psychiatrists (17\%), internal medicine doctors, internists (17\%) paediatricians (15\%) and family doctors (15\%), neurologists (5\%), gynaecologists $(5 \%)$, cardiologists $(3 \%)$, surgeons $(3 \%)$, radiologists $(3 \%)$, physiotherapists (2\%), dermatologists (2\%), ophthalmologists (2\%), pulmonologists (2\%), diabetologists (2\%), nephrologists (2\%), urologists and otolaryngologists (2\%). Other specialties amounted to about 3\%.

The percentage distribution of medical specialties in the studied group comprised doctors providing medical services to a diverse group of patients, but their common feature is that the examined doctors did not usually deal with situations related to the need to perform extremely difficult life-saving medical procedures. In the everyday professional situation of the examined group of respondents, the experienced stress and emotional burden was connected with performing daily activities resulting from the physician's work in hospital wards, clinics and surgeries, and not directly and permanently focused on the threat to a patient's life and rescue operations, as is always present in the everyday work of a surgeon, neurosurgeon, cardiac surgeon, oncologist, etc.

In order to answer the research question, it was first necessary to measure the average results allowing description of the level of stress experienced by all physicians examined, 
and then describe the average severity of the qualitative (socio-economic and demographic variables, workload) and quantitative variables (level of stress experienced and professional burnout), referring to the division of the examined doctors into two subgroups. The breakpoint was the median value: $\mathrm{Me}=24.5$. A group of doctors was distinguished with a low level of perceived stress $(\mathrm{N}=159)$ and with a high level of perceived stress $(\mathrm{N}=159)$. The average results on the scale of experienced stress for the whole sample $(\mathrm{N}=318)$ were $\mathrm{M}=23.55, \mathrm{SD}=8.01$. The minimum result obtained was two points, and the maximum - 41 points.

Analysis of ANOVA variance showed significant differences in the level of perceived stress between the group with its low $(M=16.96, S D=5.03)$ and high level $(M=30.14$, $\mathrm{SD}=3.97), \mathrm{F}=673.68, \mathrm{df}=1, \mathrm{p}<0.001$, eta $2=0.68$. First, all, the significance of differences between physicians with low and high levels of stress experienced in their lives was tested, and demographic variables (age, marital status) and socio-economic education - (specialization, scientific title) and burdens of work structure (seniority in the medical profession), work time, current number of jobs, time of daily commuting to work, frequency of changing the workplace over the last five years, team management, non-professional passions and interests and implemented in everyday life, current pharmacological treatment with antidepressants.

Further analysis excluded the variable 'primary work place; due to the fact that the vast majority of the respondents at the time of the study worked in public health $(\mathrm{N}=285 ; 90 \%)$. For quantitative variables, the normality of the distribution was checked using the Kolmogoro- Smirnov test. The results of this test confirmed a distribution close to normal for the number of years in the medical profession $(Z=1.02 ; \mathrm{p}=0.23)$. For other quantitative variables, the distribution of results differed from the normal (for the number of years of work in the basic place of work $(Z=2.18$; $\mathrm{p}<0.001)$, the number of working hours per week $(Z=2.06, p<0.001)$, and the number rosters time per month $(\mathrm{Z}=4.24 ; \mathrm{p}<0.001)$. Analyses regarding the number of years in the medical profession were carried out using Student's t-test, for the remaining variables - using the non-parametric Mann Whitney U test. The results showed that physicians with a low level of stress had longer work experience in the medical profession than doctors with a high level of perceived stress $(\mathrm{t}=2.41, \mathrm{df}=$ $316 ; \mathrm{p}=0.02)$. There were no significant differences between physicians with high and low levels of stress in the number of years of work in the primary workplace in healthcare facilities $(\mathrm{U}=11,618.5, \mathrm{p}=0.21)$, in the number of working hours per week $(\mathrm{U}=112.92, \mathrm{p}=0.10)$ and in the number of rosters a month $(\mathrm{U}=113.26, \mathrm{p}=0.09)$.

Characteristics of the level of experienced stress and level of professional burnout in a group of Polish doctors. Descriptive statistics and distribution of normality analyzes for four LBQ scales for the entire sample $(\mathrm{N}=318)$ were carried out using the Kolmogorow-Smirnow test with the Lilliefors modification. Analysis of differences between physicians with high and low level of perceived stress and their level of burnout confirmed the significance of these differences between the respondents in all components of the questionnaire measuring occupational burnout, i.e. the level of psychophysical exhaustion, engagement with patients and existential expectations - disappointment/ satisfaction (Tabl. 1).

Statistical analysis confirmed significant differences between physicians differing in the level of perceived stress for all LBQ burnout scales: exhaustion $-U=3720$; $p<0.001$; lack of commitment $-\mathrm{U}=7397$; $\mathrm{p}<0.001$; lack of professional efficacy $-\mathrm{U}=4722.5 ; \mathrm{p}<0.001$; and disappointment $-\mathrm{U}=$ $4940 ; \mathrm{p}<0.001$. The examined physicians with a high level of perceived stress at the same time showed a significantly higher severity in all three dimensions of occupational burnout, compared to physicians with a low level of perceived stress.

Regression analysis was performed in order to check which dimension of burnout was the strongest predictor of stress. An attempted was made to analyse the extent to which each of the indicators of burnout is related to levels of perceived stress. The obtained results are presented in Tables 2 and 3. The model incorporating exhaustion as the only predictor is well suited to the data: $F(1,316)=291,354 ; p<0.001$, and allows prediction of the level of perceived stress in $48 \%$ of respondents (adjusted $R^{2}=0.478$ ). Adding another variable - lack of commitment into the model, did not change its predictive value (non-significant change of $R^{2,} ; p=0.78$ ).

Table 1. Comparison of differences in the groups of physicians with low / high level of stress for the variable: occupational burnout

\begin{tabular}{|c|c|c|c|c|c|c|}
\hline Research variables: burnout & & & & & Statistics & \\
\hline doctors with low and high levels of: & $\mathbf{M}$ & SD & Min & Max & $\mathbf{U}$ & $\mathbf{p}$ \\
\hline \multicolumn{7}{|l|}{ stress } \\
\hline \multicolumn{7}{|l|}{ burnout } \\
\hline exhaustion & M & SD & Min & Max & $\mathrm{U}$ & $\mathrm{p}$ \\
\hline doctors with low level of stress & 18.11 & 38.62 & 6 & 35 & 3720 & $<0.001$ \\
\hline lack of engagement in relations & M & SD & Min & Max & $\mathrm{U}$ & $\mathrm{p}$ \\
\hline doctors with low level of stress & 16.65 & 4.96 & 6 & 36 & 7397 & $<0.001$ \\
\hline doctors with high level of stress & 20.14 & 4.12 & 9 & 31 & & \\
\hline job ineffectiveness & M & SD & Min & Max & $\mathrm{U}$ & $\mathrm{p}$ \\
\hline doctors with low level of stress & 13.89 & 4.56 & 6 & 26 & 4722.5 & $<0.001$ \\
\hline disappointment & M & SD & Min & Max & $U$ & $\mathrm{p}$ \\
\hline doctors with low level of stress & 13.81 & 6.44 & 6 & 34 & 4940 & $<0.001$ \\
\hline doctors with high level of stress & 21.6 & 6.75 & 7 & 36 & & \\
\hline
\end{tabular}


In the case of the model which included three predictors (exhaustion, lack of commitment, lack of professional efficiency), the predictive value of the model increased to $56 \%$ (significant change of $R^{2} ; p<0.001$ ). A closer look into the comlex model showed that only two variables were significant and which were related to the level of stress: exhaustion $($ Beta $=0.48 ; p<0.001)$, and lack of sense of the professional efficiency $($ Beta $=0.38 ; p<0.001)$. There was no relationship between lack of commitment and level of perceived stress $($ Beta $=-0.08 ; p=0.07)$. Adding the fourth predictor disappointment, did not change the predictive value of the model (non-significant change of $R^{2} ; p=0.94$ ). More details are presented in the Tables below.

Table 2. Summary of models which incorporate subsequent predictors for dependable variable „level of perceived stress"

\begin{tabular}{cccc}
\hline No. of predictors & $\begin{array}{c}\mathrm{R}^{2} \text { adjusted } \\
\text { coefficient }\end{array}$ & $\begin{array}{c}\text { Change of R2 adjusted } \\
\text { coefficient }\end{array}$ & $\mathrm{p}$ \\
\hline 1 & 0.48 & 0.48 & $\mathrm{p}<0.001$ \\
\hline 2 & 0.48 & 0.00 & 0.78 \\
\hline 3 & 0.56 & 0.08 & $\mathrm{p}<0.001$ \\
\hline 4 & 0.56 & 0.00 & 0.94 \\
\hline
\end{tabular}

Table 3. Summary of relations between predictors and dependent variable in selected models

\begin{tabular}{lccc}
\hline Model - predictor & Beta & $\mathrm{t}$ & $\mathrm{p}$ \\
\hline 1 & 0.69 & 17.07 & $<0.001$ \\
Exhaustion & & & \\
\hline 2 & 0.70 & 14.32 & $<0.001$ \\
Exhaustion & -0.01 & -0.28 & 0.78 \\
Lack of committment & & & \\
\hline 3 & 0.48 & 9.18 & $<0.001$ \\
Exhaustion & -0.08 & -1.81 & 0.07 \\
Lack of commitment & 0.39 & 7.76 & $<0.001$ \\
Lack of sense of professional efficiency & & & \\
\hline 4 & 0.49 & 8.28 & $<0.001$ \\
Exhaustion & -0.08 & -1.81 & 0.09 \\
Lack of commitment & 0.39 & 7.30 & $<0.001$ \\
Lack of sense of professional efficiency & -0.001 & -0.08 & 0.94 \\
Disappointment & & & \\
\hline
\end{tabular}

In the summary, obtained results indicate that significant predictors of the level of perceived stress are exhaustion and lack of proffesional efficiency. The higher the levels of exhaustion and lack of proffesional efficiency, the higher the levels of perceived stress.

Characteristics of significant correlations between level of perceived stress and demographic, organizationalprofessional and non-professional-social factors in the surveyed Polish doctors. Table 4 compares the levels of perceived stress in terms of demographic variables. Groups with a too small number of respondents were excluded from further analyses. For the variable 'marital status', the individuals who were married for the second time or more $(\mathrm{N}=17)$ and widowers $(\mathrm{N}=4)$ were excluded from the group. For the variable 'specialization', doctors with more than two specializations $(\mathrm{N}=5)$ were also excluded from further analysis. For the variable 'academic title', doctors with the title of Professor $(\mathrm{N}=5)$ were excluded. Subsequently, for the variable 'commuting time between workplaces', the individuals spending more than two hours commuting between jobs $(\mathrm{N}=8)$, were excluded.
The U Mann Whitney's test was used to compare two groups and the non-parametric Kruskal Wallis test for comparison of more than two groups. Statistically significant differences were found on the level of perceived stress in terms of specialization $(\mathrm{H}=10.02, \mathrm{df}=2 ; \mathrm{p}<0.01)$, having hobbies and pursuing interests $(\mathrm{U}=6879.50 ; \mathrm{p}<0.01)$, and frequency of taking leave during the year $(\mathrm{H}=36.42, \mathrm{df}=3$; $\mathrm{p}<0.001)$.

Pair-wise comparisons for non-parametric tests (Dunn's test) showed significant differences in the level of stress between doctors with and without a specialization $(Z=2.57$; $\mathrm{p}=0.03)$, and between physicians without specialization and those with two specializations $(Z=3.12$; $\mathrm{p}<0.01)$. Doctors without specialization declared a higher level of stress than physicians with specialization. There were no differences in the level of stress between doctors with one specialization and those with two specializations $(Z=1.26$; $\mathrm{p}=0.63)$. Physicians who had a hobby had lower level of stress than doctors without any interests $(U=6879.50 ; \mathrm{p}<0.001)$

Results of pair-wise comparisons showed significant differences between doctors who took leave more often (three or more times per year) and physicians who tended to take leave less often [vs. twice a year, $Z=2.74 ; p=0.03$; vs. once a year (no statistics); $\mathrm{p}<0.001$; vs. less than once a year, $\mathrm{Z}$ - 3.48; $\mathrm{p}<0.01$ ]. The doctors who went on holiday three or more times per year had lower level of stress compared to the other groups.

Another significant difference in the level of stress was noted between the doctors who went on the vacation once a year, and these individuals who did so twice a year $(Z=4.30$; $\mathrm{p}<0.001)$. Physicians who tend to take a leave only once a year had a higher level of stress.

In addition, there were no significant difference between doctors taking leave less than twice a year vs. once a year ( $Z$ $=-1.47 ; \mathrm{p}=0.85)$ vs. twice a year $(\mathrm{Z}=1.57 ; \mathrm{p}=0.70)$.

A difference was found for the variable 'being a team leader' $(\mathrm{U}=8240.00 ; \mathrm{p}=0.06)$. The individuals who declared being a team leader had a lower level of stress than those who did not perform this function.

There were no statistically significant differences in the level of perceived stress for other demographic variables: marital status $(\mathrm{H}=5.25, \mathrm{df}=2 ; \mathrm{p}=0.07)$, academic title $(\mathrm{U}$ $=7370.50 ; \mathrm{p}=0.69)$, current number of jobs $(\mathrm{H}=2.59, \mathrm{df}=4$; $\mathrm{p}=0.63)$, changes in employment $(\mathrm{H}=2.42, \mathrm{df}=2 ; \mathrm{p}=0.30)$, commuting time between workplaces $(\mathrm{H}=0.02, \mathrm{df}=2 ; \mathrm{p}=$ $0.99)$, working abroad $(U=1576.50 ; p=0.21)$, possession of social media account $(\mathrm{U}=10712.00 ; \mathrm{p}=0.22)$, and for taking antidepressants $(\mathrm{U}=4012.50 ; \mathrm{p}=0.19)$.

Characteristics of significant correlations between level of perceived stress, socio-economic and demographic factors and occupational burnout in the Polish doctors surveyed. Regression analysis with the application of a standard method of entry was used to study the relationship between burnout/ level of perceived stress and demographic factors. Results of the analysis are shown in Tables 5 and 6.

Variables have been transformed into a dichotomous scale and demographic factors incorporated in the analysis as predictors were:

a) marital status [nominal variable transformed into two instrumental variables: 0 - partner relationship, 1 marriage. Reference group - single];

b) specialization [0 - no specialization, 1 - having a specialization]; 
Table 4. Relations between demographic, organizational-professional, non-professional-social variables and level of stress

\begin{tabular}{|c|c|c|c|c|c|}
\hline \multirow{2}{*}{$\begin{array}{l}\text { Demografic and socialeconomic factors } \\
\text { Marital status }\end{array}$} & \multirow[b]{2}{*}{$\mathrm{N}$} & \multicolumn{4}{|c|}{ Level of stress } \\
\hline & & M & SD & $\mathrm{H}$ & $\mathrm{p}$ \\
\hline single & 52 & 23.15 & 8.94 & 5.25 & \multirow{3}{*}{ ni } \\
\hline first marriage & 199 & 23.26 & 7.76 & & \\
\hline partner relationship & 45 & 25.89 & 8.34 & & \\
\hline No. of specializations & $\mathrm{N}$ & M & SD & $\mathrm{H}$ & $\mathrm{p}$ \\
\hline 1 specialization & 197 & 23.39 & 7.96 & & \\
\hline 2 specialization & 66 & 21.79 & 8.51 & & \\
\hline Academic title & $\mathrm{N}$ & M & SD & $U$ & $\mathrm{p}$ \\
\hline No title & 250 & 23.69 & 8.14 & 7370.50 & ni \\
\hline $\mathrm{PhD} /$ working on doctoral dissertation & 61 & 23.56 & 7.57 & & \\
\hline One job & 72 & 22.28 & 8.98 & 2.59 & ni \\
\hline Two jobs & 87 & 24.53 & 8.22 & & \\
\hline Three jobs & 79 & 24.04 & 7.29 & & \\
\hline Four jobs & 43 & 24.30 & 6.12 & & \\
\hline Five and more jobs & 37 & 21.81 & 8.66 & & \\
\hline Change of employement & $\mathrm{N}$ & M & SD & $\mathrm{H}$ & $\mathrm{p}$ \\
\hline Never & 174 & 22.91 & 8.05 & 2.42 & ni \\
\hline Once & 89 & 24.63 & 7.67 & & \\
\hline 2 and more times & 55 & 23.82 & 8.33 & & \\
\hline Commuting time between workplaces & $\mathrm{N}$ & M & SD & $\mathrm{H}$ & $\mathrm{p}$ \\
\hline None & 74 & 23.45 & 8.51 & 0.02 & ni \\
\hline Less than 1 hour & 154 & 23.51 & 7.59 & & \\
\hline Are you a team leader? & $\mathrm{N}$ & M & SD & $\mathrm{U}$ & $\mathrm{p}$ \\
\hline I am a team leader & 81 & 21.96 & 7.93 & 8240.00 & tend \\
\hline I am not a team leader & 237 & 24.09 & 7.97 & & \\
\hline Have you ever worked abroad? & $\mathrm{N}$ & M & SD & $\mathrm{U}$ & $\mathrm{p}$ \\
\hline I have worked abroad & 13 & 20.15 & 10.68 & 1576.50 & ni \\
\hline I have not worked abroad & 305 & 23.70 & 7.86 & & \\
\hline Having hobbies and persuing interests & $\mathrm{N}$ & M & SD & U & $\mathrm{p}$ \\
\hline I have hobbies and persue my interests & 229 & 22,35 & 8,10 & 6879,50 & \multirow{2}{*}{$<0,001$} \\
\hline I do not have hobby and do not persue any interests & 88 & 26,58 & 6,92 & & \\
\hline Frequency of taking leave & $\mathrm{N}$ & M & SD & $\mathrm{H}$ & $\mathrm{p}$ \\
\hline Less than once a year & 41 & 24,51 & 7,48 & 36,42 & \multirow{4}{*}{$<0,001$} \\
\hline Once a year & 117 & 26,37 & 6,99 & & \\
\hline Twice a year & 131 & 22,21 & 7,82 & & \\
\hline Three and more times a year & 29 & 16,90 & 8,41 & & \\
\hline Having a social media account & $\mathrm{N}$ & M & SD & $\mathrm{U}$ & $\mathrm{p}$ \\
\hline I have a social media account & 203 & 23,05 & 8,22 & 10712,00 & $\mathrm{ni}$ \\
\hline I do not have social media account & 115 & 24,43 & 7,57 & & \\
\hline Taking anti-depressants & $\mathrm{N}$ & M & SD & $\mathrm{U}$ & $\mathrm{p}$ \\
\hline I am taking anti-depressants & 33 & 21,76 & 9,42 & 4012,50 & ni \\
\hline I am not taking ant-idepressants & 283 & 23,69 & 7,78 & & \\
\hline
\end{tabular}

c) academic title [0 - no academic title, 1 - having academic title];

d) current number of jobs [5-point ordinal scale, where a higher number means a higher number of jobs];

e) change of the employement [3point ordinal scale, where a higher number means a greater number of changes of the employement];

f) commuting time between workplaces [nominal variable transformed into two instrumental variables: 0 - less than hour, 1 - 1-2 hours. Reference group: none]; 
g)being a team leader [dychotomic variable 0 - I am not a team leader, 1 - I am team leader];

h) having a hobby [dychotomic variable: 0 - I don't have a hobby, 1 - I have a hobby];

i) frequency of taking leave [4-point ordinal scale, where a higher number means more times on vacation];

j) having a social media account [dychotomic variable: 0 - I don't have social media account, 1 - I have social media acount].

Variables 'work abroad' and 'taking anti-depressants' were not included into regression analysis, because the majority of the respondents had never worked abroad (95\%) and had never taken anti-depressants (90\%). The relationship of predictors was checked separately for every dimension of occupational burnout, and separately for the level of stress.

In the first entry, the demographic variables (marital status) were inputed. In the second entry, variables related to work (specialization, academic title, current number of the jobs, change in the employment, commuting time between workplaces, being a team leader) were imputed. In the third entry, variables not related to work (having a hobby, having a social media account, frequency of taking leave) were imputed.

The Tables present the values of $\beta$ and t coefficients derived only from the last model 3, obtained after the input of all groups of variables (division into blocks was maintained according to the order of inputing variables into the regression model). Every model had a summary which contained the significance of the model, percentage and increment of explained variance after the addition of further predictors.

Summary of model 1 involves the significance and percentage of the explained variance only by marital status. Summary of model 2 concerns significance, percentage and increment of variance explained by marital status and variables related to work. Summary of model 3 involves significance, percentage and increment of variance explained by all inputed variables (demographic, variables related and unrelated to work).

The highest percentage of variance $(14 \%)$ was explained in case of the level of perceived stress (Tab. 5, 6). The model which incorporated all variables (demographic, organizationalprofessional, non-professional-social) predicted the level of perceived stress in $14 \%$. The studies shows that after input of all predictors into the model, two professional variables had the most significant importance: specialization and being a team leader. Having a specialization and working as a team leader were related with the lowest levels of perceived stress. Furthermore, two variables unrelated to work - having a hobby and frequency of taking a leave - were significantly associated with the level of perceived stress. Having a hobby was related with less stress. Likewise, the frequency of going on holidays was negatively related to the perceived level of stress - the more often the individualwento on vacations, the lower the level of perceived stress.

Table 5. Regression analysis for independent variables (stress and burnout: exhaustion and lack of engagement) with the inclusion of demographic, organizational-professional, non-professional-social variables as predictors

\begin{tabular}{|c|c|c|c|c|c|c|}
\hline \multirow{3}{*}{$\frac{\text { Variables }}{1 . \text { Demograhic variables }}$} & \multicolumn{6}{|c|}{ Variables PSS-10, LBQ } \\
\hline & \multicolumn{2}{|l|}{ Stress level } & \multicolumn{2}{|l|}{ Exhaustion } & \multicolumn{2}{|l|}{ Lack of engagement } \\
\hline & $\beta$ & $\mathrm{t}$ & $\beta$ & $\mathrm{t}$ & $\beta$ & $\mathrm{t}$ \\
\hline Partner relationship & 0.13 & $1.86^{\wedge}$ & 0.11 & 1.60 & 0.08 & 1.09 \\
\hline Marriage & -0.01 & 0.14 & -0.03 & -0.47 & -0.05 & -0.62 \\
\hline \multirow[t]{2}{*}{ Summary of Model 1} & $F(2.273)=2.06$ & & $F(2.273)=2.17$ & & $F(2.273)=1.68$ & \\
\hline & $\Delta \mathrm{R}^{2}=0.02$ & & $\Delta \mathrm{R}^{2}=0.02$ & & $\Delta \mathrm{R}^{2}=0.01$ & \\
\hline \multicolumn{7}{|l|}{ 2. Organizational-professional variables } \\
\hline Specialization & -0.17 & $-2.93 * *$ & -0.05 & -0.82 & -0.09 & 1.09 \\
\hline Academic title & -0.05 & -0.79 & -0.12 & $-2.03^{*}$ & -0.12 & $-1.92^{*}$ \\
\hline Current No. of jobs & -0.03 & -0.45 & -0.02 & -0.31 & 0.01 & 0.05 \\
\hline Commuting time - less than 1 hour & 0.02 & 0.31 & 0.09 & 1.14 & 0.12 & 1.40 \\
\hline Commuting time $-1-2$ hurs & -0.01 & -0.16 & 0.06 & 0.76 & 0.12 & 1.37 \\
\hline Being team leader & -0.16 & $-2.76^{* *}$ & -0.19 & $-3.28^{* *}$ & -0.12 & $-1.97^{*}$ \\
\hline \multirow[t]{3}{*}{ Sumary of Model 2} & $F(9.266)=1.95^{*}$ & & $F(9.266)=2.13^{*}$ & & $F(9.266)=1.98^{*}$ & \\
\hline & $R^{2}=0.03$ & & $R^{2}=0.04$ & & $\mathrm{R}^{2}=0.03$ & \\
\hline & $\Delta \mathrm{R}^{2}=0.05^{\wedge}$ & & $\Delta \mathrm{R}^{2}=0.05^{*}$ & & $\Delta \mathrm{R}^{2}=0.05^{*}$ & \\
\hline \multicolumn{7}{|l|}{ 3. Non-professional-social variables } \\
\hline Having a hobby & -0.21 & $-3.73^{* *}$ & -0.12 & $-2.10^{*}$ & -0.15 & $-2.47^{*}$ \\
\hline Having a social media account & -0.10 & -1.73 & -0.11 & $-1.98^{*}$ & -0.08 & -1.27 \\
\hline Frequency of taking leave & -0.23 & $-3.98^{* *}$ & -0.25 & $-4.22 * *$ & -0.06 & -0.97 \\
\hline \multirow[t]{2}{*}{ Sumary of Model 3} & $F(12.263)=4.85^{* *}$ & & $F(12.263)=4.27^{* *}$ & & $F(12.263)=2.33^{* *}$ & \\
\hline & $R^{2}=0.14$ & & $\mathrm{R}^{2}=0.13$ & & $R^{2}=0.06$ & \\
\hline
\end{tabular}

$\beta$-standardized regression coefficients from the final model of the analysis; $t-t$ test of $\beta$ coefficient significance; $R 2$ - adjusted coefficient of explained variance; $\Delta R 2$ - increment of explained variance. ${ }^{*} \mathrm{p}<0.05 ;{ }^{* *} \mathrm{p}<0.01 ; \wedge \mathrm{p}<0.07$ 
Table 6. Regression analysis for independent variables (burnout: lack of sense of professional efficiency and disappointment) with the inclusion of demographic, organizational-professional, non-professional-social variables as predictors

\begin{tabular}{|c|c|c|c|c|}
\hline \multirow[b]{2}{*}{ Variables } & \multicolumn{4}{|c|}{ Variables PSS-10, LBQ } \\
\hline & Lack of sense of professional efficiency & & Disappointment & \\
\hline 1. Demograhic variables & $\beta$ & $\mathrm{t}$ & $\beta$ & $\mathrm{t}$ \\
\hline Partner relationship & 0.15 & $2.06^{*}$ & 0.03 & 0.35 \\
\hline Marriage & -0.04 & -0.57 & -0.06 & -0.80 \\
\hline \multirow[t]{2}{*}{ Summary of Model 1} & $F(2.273)=3.86^{*}$ & & $F(2.273)=0.66$ & \\
\hline & $\Delta \mathrm{R}^{2}=0.03^{*}$ & & $\Delta \mathrm{R}^{2}=0.001$ & \\
\hline \multicolumn{5}{|l|}{ 2. Orgaizational-professional variables } \\
\hline Specialization & -0.08 & -1.38 & -0.04 & -0.69 \\
\hline Academic Title & -0.11 & $-1.91 \wedge$ & -0.09 & -1.59 \\
\hline Current No. of jobs & -0.08 & -1.14 & -0.05 & -0.69 \\
\hline Commuting time - less than 1 hour & 0.06 & 0.77 & 0.001 & -0.002 \\
\hline Commuting time $1-2$ hours & 0.02 & 0.21 & 0.01 & 0.16 \\
\hline Being a team leader & -0.20 & $-3.38^{* *}$ & -0.16 & $-2.60^{*}$ \\
\hline \multirow[t]{3}{*}{ Summary of Model 2} & $F(9.266)=2.92^{* *}$ & & $F(9.266)=1.31$ & \\
\hline & $R^{2}=0.06$ & & $R^{2}=0.01$ & \\
\hline & $\Delta \mathrm{R}^{2}=0.06^{*}$ & & $\Delta R^{2}=0.04$ & \\
\hline \multicolumn{5}{|l|}{ 3. Non-professional-social variables } \\
\hline Having a hobby & -0.15 & $-2.61^{*}$ & -0.17 & $-2.95^{* *}$ \\
\hline Having a social media account & $-0,11$ & $-1,88^{\wedge}$ & $-0,13$ & $-2,17^{*}$ \\
\hline Frequency of taking leave & -0.18 & $-3.09 * *$ & -0.19 & $-3.22^{* *}$ \\
\hline \multirow[t]{2}{*}{ Summary of Model 3} & $\mathrm{~F}(12.263)=4.29^{* *}$ & & $F(12.263)=3.38^{* *}$ & \\
\hline & $R^{2}=0.13$ & & $R^{2}=0.09$ & \\
\hline
\end{tabular}

$\beta$-standardized regression coefficients from the final model of the analysis.; $t$ - $t$ test of $\beta$ coefficient significance; $R 2$ - adjusted coefficient of explained variance; $\Delta R 2$ - increment of explained variance. ${ }^{*} p<0.05 ;{ }^{* *} p<0.01 ; \wedge p<0.07$

It is worth mentioning that being in a relationship was also related to the perceived level of stress (dependency at the level of statistical tendency). Individuals who were in an informal relationship tended to be more stressed than those who were single. There was no significant correlation between the level of perceived stress and being married.

The results of relationship between indicators of burnout and demographic and professional variables were fairly consistent. Three of four burnout indicators (exhaustion, lack of sense of professional efficiency and disappointment) were significantly related to all variables non-related to work, i.e. having a hobby, possession of a social media account, frequency of taking a leave. The doctors who have a passion and social media account and often going on holidays seemed to have less intensity of burnout (for having a social media account and lack of sense of professional efficiency, the difference was at the level of tendency).

In addition, the variable 'having a hobby' was related to the fourth indicator of burnout - lack of work engagement. Having a hobby was associated with higher work engagement. Occupational burnout was also related to the function performed by the person at work, e.g. working as a team leader was associated with a lower intensity of professional burnout. This dependency was stronger for the lack of professional efficiency and exhaustion.

Another professional variable, 'academic title', was associated with exhaustion and lack of professional efficiency at the level of tendency. Possession of an academic title indicated a lower intensity of these two dimensions of burnout.

One of the dimensions of burnout proved to be significantly related to marital status. This means that individuals who were in relationship (but not married) felt a greater lack of professional efficiency than those who were single.

After inclusion of all variables, the percentage of the explained variance in the case of burnout was quite similar: $13 \%$ for exhaustion and lack of professional efficiency, 9\% for disappointment and $6 \%$ for lack of commitment. The model which included all demographic, organizational-professional and non-professional-social variables predicted the intensity of occupational burnout from $6 \%$ (lack of commitment) $13 \%$ (exhaustion).

In conclusion, the demographic variable (staying in an informal relationship) was related with a higher level of perceived stress and the feeling of lack of sense of professional efficiency. Working as a team leader and having a hobby was associated with the stress level and all dimensions of burnout. The frequency of going on vacations was related to the level of stress and indicators of burnout, except the lack of commitment. None of the dependent variables significantly related to such professional variables as current number of jobs, change of employment and commuting time between workplaces. 


\section{DISCUSSION}

First, it must be emphasized that in the presented study it was quite challenging to make a comparison between the obtained results and similar research results for three important reasons. 1) Numerous studies conducted todate have used various tools addressing the problem of occupational burnout among medical professionals. The most frequently used tools were the Maslach Burnout Inventory (MBI) [44]; contemporary, modified versions of the Human Services Survey (MBI-HSS) and the General Survey (MBIGS) [45], Occupational Burnout Scale (OBS) [46], Shirom Melamed Burnout Measure (SMBM) [47], Copenhagen Burnout Inventory (CBI) [48], The Burnout Scale [49] and Tedium Index [50]. All these tools refer to Maslach's burnout concept.

The first of the axial symptoms of this concept - exhaustion is consistently shared by the majority of researchers. However, the third and in particular the second symptom depersonalization, causes doubts and divide the researchers studying this issue $[51,52]$. According to the International Statistical Classification of Diseases and Health Problems (ICD-10), depersonalization is a rare disorder in which the patient spontaneously complains about a qualitative change in mental, physical and environmental performance. Symptoms of depersonalization may also appear as an element of schizophrenia, depression, phobia or obsessivecompulsive disorder [53, 54].

Christina Maslach believes that burnout is not a psychopathological phenomenon, but rather a multifaceted syndrome of symptoms. Currently, this concept is criticized as being theoretically inconsistent $[51,55,56,57$, 58]. Therefore, in the current study it was decided to use tools for measuring burnout other than the afore-mentioned in the research. The LBQ questionnaire [41] allows assessment of not three, but four aspects of professional burnout. While the first three subscales correspond to the symptoms of the progressing burnout process according to Maslach's concept, and reflect the psychophysical aspect of burnout, the last subscale - disappointment - refers rather to the existential concept. This dimension perceives motivation to work as a mission and also meaning in life.

Secondly, most of the research carried out over the last two decades covered the issue of professional burnout of medical professionals, focusing mainly on nurses [59]. The medical professions of nurses and doctors are highly exposed to stress and occupational burnouts; however, they differ, and thus the patients' expectation is slightly different [60]. Maslach [42] emphasizes that professional burnout particularly affects people whose work concerns providing social services, requires close and direct work with people, personal involvement and interpersonal contacts. Social skills and competences are their basic work tools. This has been clearly indicated in many studies [61], and although this is not the rule, it should be emphasized that the patients' contact with nurses is more frequent than with a doctor. There is also a smaller social distance in nurse-patient relations due to different social positions of the doctor and nurse professions $[62,63,64]$. The burnout process will therefore have a different course due to other work missions, which is rarely shown in research.

Thirdly, studies on occupational burnout in medical professions which contained variables other than personal or the work-related environment, were considered moderators of burnout and stress. The most often analyzed factors were demographic: age, gender and marital status, less frequently organizational and professional: experience, place of employment (ward), salary, workload and support from co-workers. With the exception of the last three variables from the group of organizational and occupational factors, the results obtained for other demographics, including organizational and professional, were ambiguous $[59,65,66]$. In the current study, the list of organizational-professional factors was enlarged with additional variables and the introduction of new categories of non-professional and social variables as moderators of burnout. This direction of analysis is in line with the suggestion of Maslach [42], who indicated the need to integrate many non-professional factors as potential moderators or mediators of the burnout process. Analysis of the latter has been undertaken only in a few studies in recent years and have mainly concerned the raising of professional qualifications $[67,68]$, resident status $[69,70]$, or having children [70]. In the current study, this list has been extended with additional variables: having a hobby, social networking accounts and frequent vacation trips.

The results obtained in this study are in line with some of the previously detected relationships, and have also indicated others which have not been previously observed. It was assumed that some of the burnout variables will be important predictors of stress for doctors, and analysis of the obtained results confirmed this assumption, thus indicating that burnout was enhanced most of all by exhaustion, followed in second place by the feeling of lack of involvement. This result is consistent with other studies in which a similar trend was detected [71, 72].

As previously mentioned, the results of research concerning the relationship between stress, occupational burnout and demographic factors in the group of doctors, are ambiguous. This applies in particular to the variables: age and marital status $[23,47,62,73,74,75,76]$. The analysis in the current study included variable 'marital status; which in many studies confirmed that being in a more stable relationship is a more important predictor for reducing stress and burnout symptoms, than the age of the individual. As predicted in the current study, it turned out that marital status (all categories) is not significantly related to the level of experienced stress. However, taking into consideration the combined relationships of stress and occupational burnout, being in a partner relationship strengthens both the stress and occupational burnout, especially in the area of lack of professional effectiveness. These results are consistent with other studies $[75,76,77,78,79]$. It should also be remembered that in Poland, the professional stereotype of a single person is still strong as a more available profession, and was widespread in the previous socio-economic system. On the other hand, it is surprising to obtain a result that indicates being married is not correlated with the analyzed independent variables, and is not their predictor. This result does not authenticate the claim that marriage makes doctors more resistant to stress at work and occupational burnout, or vice versa, but indicates that in subsequent studies one should look for an additional mediator of these relationships. Perhaps subsequent studies should investigate such areas as having children or family-work relationships, as underlined in a later part of the Discussion. It is also worth emphasizing that being in a partner relationship proved to be a predictor 
of only one of the dimensions of professional burnout - a sense of lack of professional efficiency and, at the level of tendency, experiencing stress.

Nowadays, doctors working in both public and private institutions find it increasingly difficult to see the progress they are making since appreciation is rarely shown by the patients. In the era of competition and the pursuit of success, the practice of showing support to colleagues is also disappearing. Probably they also do not receive this from their life partners. Meanwhile, appreciating oneself as an effective person is an important aspect of psychological well-being, because it reinforces the sense of value, and most importantly, commitment to the medical profession.

The next group of predictors, referred to by the authors of this study as 'organizational-professional', belong to the most complex predictors, and have taken into account the variables already identified in earlier studies (upgrading qualifications, professional experience, specialization), and new ones that have not been recognized to-date (team leader function, commuting between successive jobs, change of employment, work abroad, number of employment, degrees and academic titles).

It was proved that having only specialization was related to stress, while being a team leader at the level of the tendency. Having a specialization, in contrast to not having one, can significantly relieve stress. However, this process is not strengthened by having additional specializations; hence, raising qualifications in the horizontal structure. Analysis of the organizational and professional variables as predictors of stress and occupational burnout showed an increased explanatory variance of the problem. This applies to both variables. In the case of professional burnout, the features of predictor in all four areas of burnout, obtained a variable of being a team leader and having an academic title in relation to the first three dimensions of burnout (exhaustion, lack of involvement with the patient and a sense of inefficiency). In conclusion, among other things, holding a managerial position or being the head of a medical team can protect Polish doctors against stress and occupational burnout. Having an academic or a scientific title protects against the effects of professional burnout, and having a specialization protects against susceptibility to stress. In particular, the latter variable requires therefore comment. Several studies have shown that doctors working in the departments of surgery, pediatrics, gynecology and emergency medicine, are more likely to burnout due to the demanding nature of these wards $[62,80,81]$. Since the research description does not state whether work at a given branch is clearly associated with specialization, it is difficult to refer to these results and compare them with those obtained in the current study.

Surprising results were obtained in relation to other organizational-professional variables. These included commuting time between successive jobs, change in employment, working abroad, and the number of work positions, which neither gain the predictive character nor are related to stress and burnout. These categories were deliberately expanded in the current study, bearing in mind that many studies have reported that the workload strengthens these processes [19, 68, 82, 83, 84]. Commuting between numerous employees or jobs, as well as frequent changes in employment, seem to make it easier to distance oneself from problems in a given workplace. Involvement in the treatment process in a specific case is probably not so deep, in contrast to the situation in which doctors are associated with only one medical facility.

Finally, the category of non-professional-social variables turned out to be a group of variables that remained not only in the strongest relationships with both analyzed processes, but they were also their important predictors. This applies in particular to having a hobby and frequent use of leaves. These variables alleviate all symptoms of burnout and experiencing stress.

An interesting result is also the detection of the predictive impact of having an account on social networks, and the mitigating effects of burnout in two symptoms: exhaustion and disappointment. This is an original result, indicating that the virtual community provides individuals (including doctors, according to research by the authors of the presented study) with significant support and protection against social isolation. Furthermore, it strengthens their enthusiasm, confirming the conviction that it is worth working for another human being. Referring to these data, it should be noted that these are important coping regulators which have not been mentioned to-date in studies on occupational burnout.

Summing-up the discussion of results, there is a need to undertake research seeking moderators and mediators in the area not only of personal or organizational variables of stress and burnout in doctors, but also in the non-professional and social variables. A good direction would be to look for relationships between stress and burnout vs. family-work relations. This would allow a wider diagnosis of the role of families in the regulation of these processes. It is true that this problem has been undertaken in several studies carried out to-date; however, in the opposite direction of the workfamily relationship $[82,85]$.

Taking into account the health of the individual, it is extremely important that the work-family and personal relationships are in complete balance (work-life balance) [86]. This is possible due to changes in the work organization, working time, and the various facilities for employees with families introduced by the organizations; hence, hospitals. Workplaces are not always willing to take into account family preferences or the personal life of doctors.

It should also be remembered that health care institutions adapted to external conditions and began to use downsizing, i.e. a group of activities undertaken by management in order to improve its efficiency and competitiveness on the market. Downsizing, which is usually associated with staff reduction, consists in reducing the costs of the enterprise, and is inevitably associated with the dismissal of doctors ('downsizing'), in particular those who are single and do not have a family. Downsizing affects not only those who are made redundant, but also the employees who remain in the organization. They become more stressed, have more responsibilities and are afraid that the timeline will be cut. The literature mentions even a 'workplace survivor syndrome', which defines the persons remaining in the organization during layoffs. Referring to the above-described syndrome, this can explain the stronger professional burnout observed in the examined single doctors. 


\section{CONCLUSIONS}

Problems related to occupational burnout cannot be underestimated, even in the group of professionals involved in the treatment to which doctors belong, as evidenced by the results of many studies. Professional burnout of doctors leads to psychosomatic problems, such as insomnia, irritability and problems with social relations [71, 87]; increase in the risk of cardiovascular diseases [88], and increase in cholesterol, triglycerides, glucose and uric acid levels in blood [71]. A long-lasting burnout process leads to irreversible physiological changes [89] and even to post-traumatic stress disorder (PTSD), as well as predisposes to alcohol abuse and suicidal thoughts [90]. Doctors, who suffer burnout often decide to take early retirement $[91,92]$. As a professional group, doctors also need assistance and personal treatment to experience a good quality of life at work and outside work. Therefore, the constant search for various moderators and mediators of professional burnout among doctors and studying this problem, is justified, even if they result in subsequent conceptual replications.

\section{REFERENCES}

1. Walkiewicz M, Zalewski B. Psychospołeczny portret lekarza w Polsce [Psychosocial profile of Polish doctors]. Medycyna po dyplomie 2017. https: //www.researchgate.Net/publication/317258972. Polish.

2. Walkiewicz M, Sowińska K, Tartas M. Wypalenie zawodowe - przegląd literatury. Prz Lek. 2014; 71(5): 263-269.

3. Arora M, Asha S, Chinnappa J, Diwan AD. Burnout in emergency medicine physicians. Emergency Medicine Australasia. 2013; 25: 491-495. http//doi.org/10.1111/1742-6723.12135

4. Pantenburg B, Luppa M, König HH, Riedel-Heller SG. Burnout among young physicians and its association with physicians' wishes toleave: results of a survey in Saxony, Germany. J Occup Med Toxicol. 2016; 11: 2. http//doi.org/10.1186/s12995-016-0091-z

5. Eelen S, Bauwens S, Baillon C, Distelmans W, Jacobs E, Verzelen A. The prevalence of burnout among oncology professionals:oncologists are at risk of developing burnout. Psycho-Oncology. 2014; 23: 1415-1422. http//doi.org/10.1002/pon.3579

6. Petitta L, Jiang L, Härtel, Ch EJ. Emotional contagion and burnout among nurses and doctors: Do joy and anger from different sources of stakeholders matter? Stress and Health. J Inter Soc Invest Stress. 2017; 33(4): 358-369.

7. Xinyu Z, Juncai P, Xiaoni Z, Dan Z, Dinghong Y, Lining Y, et al. Burnout, psychological morbidity, job stress, and job satisfaction in Chinese neurologists. Neurology. 2017; 88(18): 1727-1735.

8. Maslach Ch, Leiter M. Understanding the burnout experience: recent research and its implications for psychiatry. World Psychiatry. 2016; 15(2): 103-111.

9. Lin F, Winsome SJ, McVeigh C. Burnout among hospital nurses in China. J Nurs Manag. 2009; 17: 294-301. https://doi.org/10.1111/j.13652834.2008.00914.x

10. Greenglass ER, Burke RJ, Fiksenbaum L. Worlkoad and burnout in nurses. J Community. Appl Soc Psychol. 2001; 11: 211-215, https://doi. org/10.1002/casp.614.

11. Sasaki M, Kitaoka-Higashiguchi K, Morikawa Y, Nakagawa H. Relationship between stress coping and burnout in Japanese hospital nurses. J Nurs Manag. 2009; 17: 359-365. https://doi.org/10.1111/j.13652834.2008.00960.x

12. Hsu HY, Chen SH, Yu HY, Lou JH. Job stress, achievement motivation and occupational burnout among male nurses. J Adv Nurs. 2010; 66: 1592-1601. https://doi.org/10.1111/j.1365-2648.2010.05323.x

13. Tunc T, Kutanis RO. Role conflict, role ambiguity and burnout in nurses and physicians of university hospital in Turkey. Nurs Health Sci. 2009; 11: 410-416. https://doi.org/10.1111/j.1442-2018.2009.00475.x

14. Kowalski C, Ommen O, Driller E, Erstmann E, Wirtz MA, et al. Burnout in nurses - the relationship between social capital in hospitals and emotional exhaustion. J Clin Nurs. 2009; 19: 1654-1663. https:// doi.org/10.1111/j.1365-2702.2009.02989.x
15. Shirom A, Nirel N, Vinokur AD. Work hours and caseload as predictors of physician burnout: the mediating effects by perceived workload and by autonomy. Appl Psychol. 2010; 59: 539-565. https://doi.org/10.1111/ j.1464-0597.2009.00411.x

16. Alacacioglu A, Yavuzsen T, Dirioz M, Oztop I, Yilmaz U. Burnout in nurses and physicians working a tan oncology department. Psychooncology. 2009; 18: 543-548.

17. Ratanawongsa M, Roter D, Beach MC, Laird SL, Larson SM, et al. Physician burnout and patient-physician communication during primary care encounters. J Gen Intern Med. 2008; 23: 1581-1588. https://doi.org/10.1007/s11606-008-0702-1

18. Hanrahan NP, Aiken LH, Mc Claine L, Hanlon AL. Ralationship between psychiatric nurse work environments and nurse burnout in acute care in generale hospitals. Issues Ment Health Nurs. 2010; 31: 198-207. https://doi.org/10.3109/01612840903200068

19. Ozyurt A, Hayran O, Sur H. Predictors of burnout and job satisfaction among Turkish physicians. QJM. 2006; 99: 161-169. https://doi. org/10.1093/qjmed/hcl019

20. Panagopoulu E, Montgomery A, Benos A. Burnout in internal medicine physicians: differences between residents and specialists. Eur J Intern Med. 2006; 17: 195-200. https://doi.org/10.1016/j.ejim.2005.11.013

21. Bruce SM, Conaglen HM, Conaglen JV. Burnout in physicians: a case for peer - support. Intern Med. J. 2005; 35: 272-278. https://doi. org/10.1111/j.1445-5994.2005.00782.x

22. Peltzer K, Mashego TA, Mabeba M. Short Communication: Occupational stress and burnout among South African medical pracitioners. Stress Health. 2003; 19: 275-280. https://doi.org/10.1002/smi.982.

23. McManus IC, Winder BC, Gordon D. The causal links between stress and burnout in a longitudinal study of UK doktors. Lancet. 2002; 359: 2089-2090.

24. Kovatcs M, Kovatsc E, Hegedus K. Emotion work and burnout: cross sectional study of nurses and physicians in Hungary. Croat Med J. 2010; 51: 432-442. https: doi.org/10.3325/cmj.2010.51.432

25. Lee H, Song R, Cho Y, Lee GZ, Daly B, et al. Comprehensive model for predicting burnout in Korean nurses. J Adv Nurs. 2003; 45: 534-545.

26. Freeborn DK. Satisfaction commitment and psychological well-being among HMO physicians. West J Med. 2001; 174: 13-18.

27. Dewa CS, Jacobs P, Thanh NX, Loong D. An estimate of the cost of burnout on early retirement and reduction in clinical hours of practicing physicians in Canada. BMC Health Services Research. 2014; 14: 254. https://doi.org/10.1186/1472-6963-14-254.

28. Moreno-Jimenez B, Rodriguez-Carvajal R, Hernandez EG, Benadero EM. Terminal versus non-terminal care in physician burnout: the role of decision - taking processes and attitudes to death. Salud Ment. 2008; 31: 93-101.

29. Dudek B, Waszkowska M, Merecz D, Hanke W. Ochrona zdrowia pracowników przed skutkami stresu zawodowego. Łódź: Nofer Institute of Occupational Medicine; 2004.

30. Sęk H. Poznawcze i kompetencyjne uwarunkowania wypalenia w pracy z chorymi. Post Psych Neurol. 2005; 14(2): 93-98.

31. Weston G, Zilanawala A, Webb E, Carvalho LA, McMunn A. Long work hours, weekend working and depressive symptoms in men and women: findings from a UK population-based study. J Epidemiol Community Health. 2019; 0: 465-474. doi: 10.1136/jech-2018-211309

32. Czabak-Garbacz E, Stasiuk W, Zakrocka IN, Cygan B, Furtak I. Stres zawodowy w pracy lekarzy w szpitalu i w przychodni. Zdr Publ. 2012; 122(3): 298-301.

33. Krysiak L. [Polish health service in the tail of Europe]. Gaz Lek. 2015; 3. Polish.

34. Mickiewicz I, Krajewska-Kułak E, Kędziora-Kornatowska K, Muszyńska-Rosłan K. [Selected Problems Related to Working in Oncology Departments and Hospices]. Prace Poglądowe. Piel Zdr Publ. 2011; 1(4): 343-352, ISNN 2082-9876. Polish.

35. Ostrowski MT. [Positive and negative consequences of having more than one job for doctors' health]. Pol Forum Psychol. 2009; 14(1): 78-89. Polish.

36. Ogńska-Bulik N. [Professional stress in social services professions]. Warszawa: Difin; 2006, Polish.

37. Freudenberger HJ. Staff burnout. J Soc Issues. 1974; 30(1): 159-165.

38. Pines AM. Couple burnout: Causes and Cures. New York: Routledge. 1996.

39. Sęk H. Uwarunkowania i mechanizmy wypalenia zawodowego w modelu społecznej psychologii poznawczej. W: H. Sęk (red.), Wypalenie zawodowe. Przyczyny, mechanizmy, zapobieganie. Warszawa: Wydawnictwo Naukowe PWN; 2000: 83-112.

40. Tucholska S. Wypalenie zawodowe u nauczycieli. Psychologiczna analiza zjawiska i jego osobowościowych uwarunkowań. Lublin: Wydawnictwo Katolickiego Uniwersytetu Lubelskiego. 2009. 
41. Santinello M. LBQ Link Burnout Questionnaire. Manuale. Firenze: Giunti O.S. Organizzazioni Speciali. 2008.

42. Maslach C. Engagement research: Some thoughts from a burnout perspective. Eur J Work Organizational Psychol. 2011; 20: 47-52.

43. Juczyński Z, Ogińska-Bulik N. Skala Odczuwanego Stresu - PSS-10. Narzędzia pomiaru stresu i radzenia sobie ze stresem. Warszawa: Pracownia Testów Psychologicznych PTP Polskiego Towarzystwa Psychologicznego, 2009; Polish.

44. Maslach Ch, Schaufeli WB, Leiter MP. Job burnout. Annu Rev Psychol. 2001; 52: 397-422.

45. Lin F, St John W, McVeigh C: Burnout among hospital nurses in China. J Nurs Manag. 2009: 17; 294-301.

46. Hsu HY1, Chen SH, Yu HY, Lou JH. Job stress, achievement motivation and occupational burnout among male nurses. J Adv Nurs. 2010; 66(7): 1592-601. doi: 10.1111/j.1365-2648.2010.05323.x

47. Shirom A, Nirel N, Vinokur AD. Work hours and caseload as predictors of physician burnout: the mediating effects by perceived workload and by autonomy. Appl Psychol. 2010; 59: 539-565. doi: 10.1111/j.14640597.2009.00411.x

48. Kristensen TS, Borritz M, Villadsen E, Christensen KB. The Copenhagen Burnout Inventory: A new tool for assessment of burnout. Work \& Stress. 2007; 19(3): 192-207. doi: 10.1080/02678370500297720

49. Kushnir T, Cohen AH: Job structure and burnout among primary care paediatricians. Work. 2006; 27: 67-74.

50. Freeborn DK. Satisfaction, commitment and psychological well-being among HMO physicians. West J Med. 2001; 174: 13-18.

51. Kristensen TS, Borritz M, Villadsen E, Christensen KB. The Copenhagen Burnout Inventory: A new tool for the assessment of burnout. Work \& Stress. 2005; 19(3): 192-207.

52. Demerouti E, Mostert K, Bakker AB. Burnout and work engagement: a thorough investigation of the independency of both constructs. J Occup Health Psychol. 2010; 15: 209-222. doi: 10.1037/a0019408

53. Rybakowski J, Pużyński S, Wciórka J. Podstawy psychiatrii. Tom 1. Elsevier Urban \& Partner, Wrocław, 2010.

54. Maslach Ch, Leiter M. Understanding the burnout experience: recent research and its implications for psychiatry. World Psychiatry. 2016; 15(2): 103-111. doi: 10.1002/wps.20311

55. Lloyd C, King R, Chenoweth L. Social work, stress and burnout: A review. J Mental Health. 2002; 11(3); 255-266. http://dx.doi. org/10.1080/09638230020023642

56. Demerouti E, Bakker AB, Vardakou I, Kantas A. The convergent validity of two burnout instruments: a multitrait-multimethod analysis. Eur J Psychol Assess. 2003; 19: 12-23.

57. Evans S, Huxley P, Gately C, Webber M, Mears A, Pajak S, at all. Mental health, burnout and job satisfaction among mental health social workers in England and Wales. B J Psychiatry. 2006; 188: 75-80. doi: 10.1192/bjp.188.1.75

58. Mańkowska B. Podmiotowe i organizacyjne wyznaczniki wypalenia zawodowego pracowników pomocy społecznej. Prz Psychol. 2015; 58(1): 83-97.

59. Walkiewicz M, Sowińska K, Taras M. Wypalenie zawodowe wśród personelu medycznego - przegląd literatury. Przegl Lek. 2014; 71(5): $263-269$.

60. Biela A. European Questionnaire for Job Analysis, Berlin. Peter Lang Gmbh. 2018.

61. Sasaki M, Kitaoka-Higashiguchi K, Morikawa Y, Nakagawa H. Relationship between stress coping and burnout in Japanese hospital nurses. J Nurs Manag. 2009; 17: 359-365. doi:10.1111/j.13652834.2008.00960.x

62. Wen J, Cheng Y, Hu X, Yuan P, Hao T, Shi. Workload, burnout, and medical mistakes among physicians in China: A crosssectional study. Biosci Trends. 2016; 1: 27-33. doi: 10.5582/bst.2015.01175

63. Wu Liu L, Wang Y, Gao F, Zhao X, Wang. Factors associated with burnout among Chinese hospital doctors: a crosssectional study. BMC Public Health 2013; 13: 1-12. doi: 10.1186/1471-2458-13-786

64. Azam K, Khan A, Alam MT. Causes and Adverse Impact of Physician Burnout: A Systematic Review. J Coll Physicians Surg Pak. 2017; 27(8): 495-501. doi: 2678

65. Banerjee A. Physician Heal Thyself: Perspectives on Burnout among Doctors. Perspectives Med Res. 2019; 7(1): 3-9.

66. Garcia HA, McGeary CA, Finley EP, Ketchum NS, McGeary D, Peterson. Burnout among psychiatrists in the Veterans Health Administration. Burn Res. 2015; 4: 108-14.

67. Pantenburg B, Luppa M, König H, Riedel-Heller S. Burnout among young physicians and its association with physicians' wishes to leave: results of a survey in Saxony, Germany. J Occup Med Tox. 2016; 11 : 1-10. doi: 10.1186/s12995-016-0091-z

68. Zubairi AJ, Noordin S. Factors associated with burnout among residents in a developing country. Ann Med Surg. 2016; 6: 60-63. doi: 10.1016/j. amsu.2016.01.090

69. Kimo Takayesu J, Ramoska EA, Clark T, Hansoti B, Dougherty J, Freeman W. Factors associated with burnout during emergency medicine residency. Acad Emerg Med. 2014; 9: 1031-1035. doi: 10.1111/ acem. 12464

70. Langade D, Modi PD, Sidhwa YF, et al. Burnout Syndrome Among Medical Practitioners Across India: A Questionnaire-Based Survey. Cureus. 2016; 8(9): e771. doi 10.7759/cureus.771

71. Lo D, Wu F, Chan M, Chu R, Li D. A systematic review of burnout among doctors in China: a cultural perspective. Asia Pac Fam Med. 2018; 17: 3. https://doi.org/10.1186/s12930-018-0040-3

72. Al-Turki HA, Al-Turki RA, Al-Dardas HA, Al-Gazol MR, Al-Maghrabi $\mathrm{GH}$. et al: Burnout syndrome among multinational nurses working in Saudi Arabia. Ann Afr Med. 2010; 9; 226-229. doi: 10.4103/15963519.70960

73. Meeusen V, Van Dam K, Brown-Mahoney C, Van Zendert A, Knapa H. Burnout, psychosomatic symptoms and job satysfaction among Dutch anaesthetists: a survey. Acta Anaesthesiol Scand. 2010; 54: 616-621. https://doi.org/10.1111/j.1399-6576.2010.02213.x

74. Wang Z, Xie Z, Dai J, et al. Physician burnout and its associated factors: a cross-sectional study in Shanghai. J Occup Health. 2014; 56: 73-83. https://doi.org/10.1539/joh.13-0108-OA

75. Siu C, Yuen S, Cheung A. Burnout among public doctors in Hong Kong: cross-sectional survey. Hong Kong Med J. 2012; 3: 186-92.

76. Howard M. The incidence of burnout or compassion fatigue in medical dosimetrists as a function of various stress and psychologic factors. Med Dosimetry. 2013; 1: 88-94. doi: 10.1016/j.meddos.2012.07.006

77. Yao S, Yu H, Ai Y, Song P, Meng S, Li W. Job-related burnout and the relationship to quality of life among Chinese medical college staff. Arch Environ Occup Health. 2015; 1: 27-34. doi: $10.1080 / 19338244.2013 .859120$

78. Lamothe M, Boujut E, Zenasni F, Sultan S. To be or not to be empathic: the combined role of empathic concern and perspective taking in understanding burnout in general practice. BMC Family Prcat 2014; 1: 1-7. https://doi.org/10.1186/1471-2296-15-15

79. Jalili M, Roodsari GS, Nia A. Burnout and associated factors among Iranian emergency medicine practitioners. Iranian J Pub Health. 2013; 9: 1034.

80. Saijo Y, Chiba S, Yoshioka E, Kawanishi Y, Nakagi Y, Itoh T. Effects of work burden, job strain and support on depressive symptoms and burnout among Japanese physicians. Int J Occup Med Env Health. 2014; 6: 980-992. doi: https://doi.org/10.2478/s13382-014-0324-2.

81. Al-Dubai SA, Rampal KG. Prevalence and associated factors of burnout among doctors in Yemen. J Occup Health. 2010; 52: 58-65. https://doi. org/10.1539/joh.O8030

82. Kapucu SS, Akkus Y, Akdemir N, Karacan Y: The burnout and exhaustion levels of nurses working in haemodialysis units. J Ren Care. 2009; 35: 134-140. doi: 10.1111/j.1755-6686.2009.00108.x

83. Vedsted P, Sokolowski I, Olesen F. Open access to general practice was associated with burnout among general practitioners. Int J Family Med. 2013; 1-6. doi: 10.1155/2013/383602.

84. Wang Liu L, Wang J, Wang L. Work-family conflict and burnout among Chinese doctors: the mediating role of psychological capital. J Occup Health. 2012; 54: 232-240.

85. Heiligers PJM, Hingstman L. Career preferences and the work-family balance in medicine: gender differences among medical specialists. Soc Sci Med. 2000; 50: 1235-1246.

86. Salanova M, Llorens S: Current state of research on burnout and future challenges. Papeles del psicólogo. 2008; 29: 59-67.

87. Melamed S, Kushnir T, Shirom A: Burnout and risk factors for cardiovascular diseases. Behav Med. 1992; 18: 53-60. 10.1080/08964289.1992.9935172

88. Danhof-Pont M, van Veen T, Zitman FG. Biomarkers in burnout: a systematic review. J Psychosom Res. 2010; 70(6): 505-524. doi: 10.1016/j. jpsychores.2010.10.012

89. Lemaire JB, Wallace JE, Burnout among doctors. BMJ. 2017; 358: j3360. doi: https://doi.org/10.1136/bmj.j3360 011; 70: 50524

90. Henkens K, Leenders M. Burnout and older workers' intention to retire. Int J Manpow. 2010; 31(3): 306-321. doi: 10.1108/01437721011050594.

91. Dewa C S, Loong D, Bonato S, Thanh N X, Jacobs P. How does burnout affect physician productivity? A systematic literature review. BMC Health Serv Res. 2014; 14: 325. doi: 10.1186/1472-6963-14-325 